\title{
The effect of IL-17 blockage on the neutrophil to lymphocyte ratio in patients with axial spondyloarthritis: a comparative study with anti-TNF
}

\author{
Elem Yorulmaz $®$, Duygu Geler Külcü®
}

Department of Physical Medicine and Rehabilitation, University of Health Sciences, Haydarpaşa Numune Training and Research Hospital, Istanbul, Turkey

\begin{abstract}
Objectives: This study aims to evaluate the neutrophil to lymphocyte ratio (NLR) and platelet to lymphocyte ratio (PLR) in patients with axial spondyloarthritis receiving different biologic treatments.

Methods: The study included 33 axial spondyloarthritis patients (20 males, 13 females) receiving anti-TNF or secukinumab therapy. Patients' age, disease duration, ongoing therapy duration, serum C-reactive protein (CRP) and erythrocyte sedimentation rate (ESR), neutrophil, lymphocyte and platelet counts, Bath Ankylosing Spondylitis Disease Activity Index (BASDAI) scores, NLR, and PLR were recorded retrospectively.

Results: The patients' mean age was 44 years, and the disease's mean duration was 121.55 months. Fourteen $(42.4 \%)$ patients were receiving secukinumab, $57.6 \%$ of the patients were receiving anti-TNF agents. The male/female ratio was $6 / 8$ in the secukinumab group and $14 / 5$ in the anti-TNF group. The ongoing therapy duration was $8 \pm 5.1$ months for the secukinumab group and $27 \pm 27.6$ months for the anti-TNF group. Only NLR was significantly higher in the secukinumab group, and there was no other statistical difference between groups. There was no correlation between NLR, PLR, and CRP, ESR, BASDAI.

Conclusions: The results of our study show that only NLR is significantly higher in the secukinumab group compared to the anti-TNF group. Hence NLR may be a useful and sensitive parameter in terms of monitoring disease activity.

Keywords: .Axial spondyloarthritis, neutrophil to lymphocyte ratio, platelet to lymphocyte ratio, secukinumab
\end{abstract}

Npondyloarthritis ( $\mathrm{SpA})$ is a term used to describe a group of chronic rheumatological diseases such as ankylosing spondylitis (AS), psoriatic arthritis, reactive arthritis, and so on. It is classified clinically as peripheral SpA and axial SpA. Axial SpA is characterized by inflammatory back pain, sacroiliitis, spondylitis, and limited spinal motion [1]. There is no standard laboratory test defined to be used in the di- agnosis or follow-up of this disease group. Erythrocyte sedimentation rate (ESR) and C-reactive protein (CRP), indicators of inflammation, and Bath Ankylosing Spondylitis Disease Activity Index (BASDAI), an indicator of the clinical activity of the disease, are used in follow-ups. Serum ESR and CRP levels are usually increased in SpA, especially in cases with peripheral joint involvement. Both tests have low sensitivity and

How to cite this article: Yorulmaz E, Geler Külcü D. The effect of IL-17 blockage on the neutrophil to lymphocyte ratio in patients with axial spondyloarthritis: a comparative study with anti-TNF. Eur Res J 2023:9(1):8-13. DOI: 10.18621/eurj.886700

Address for correspondence: Elem Yorulmaz, MD., University of Health Sciences, Haydarpaşa Numune Training and Research Hospital, Department of Physical Medicine and Rehabilitation, Selimiye Mah., Tıbbiye Cad., No:23, 34668 Üsküdar, Istanbul, Turkey. E-mail: eleminal@gmail.com, Phone: +90 02165423232 ext. 3890 
specificity and do not reflect the disease process ultimately. Elevation of either one of them is observed in only $50 \%$ of patients with AS. BASDAI, which is routinely used, is only a reflection of the disease activity assessment, does not include the physician's disease evaluation, and is not a direct indicator of inflammation [2]. It is known that there are changes in the amount and composition of circulating blood cells in systemic inflammation. In studies based on this knowledge, it has been suggested that neutrophil-lymphocyte ratio (NLR) and platelet lymphocyte ratio (PLR) increase in many rheumatologic diseases with inflammation and can be used as a marker of the inflammatory process $[3,4]$. They were also shown as increased in most of the studies on AS [5-13]. A survey of patients with AS who received anti-tumor necrotizing factor (Anti-TNF) treatment concluded that NLR could be a useful marker for monitoring response to treatment [12]. Another study on AS found that NLR was lower in anti-TNF therapy patients than those followed-up with non-steroidal anti-inflammatory drugs [13]. It is known that interleukin-17 (IL-17) has synergistic effects with TNF- $\alpha$ and IL-1 on cytokine induction and tissue destruction. However, it has shown that it can act independently [14]. Therefore, secukinumab, an IL-17 inhibitor, may have different effects on inflammation and its markers than TNF inhibitors. There is no study evaluating the impact of various biological treatments on the NLR in the literature. Our research aims to compare the two groups' hematological parameters receiving different biological therapies in patients with axial SpA.

\section{METHODS}

Thirty-three patients (20 males, 13 females) classified as axial SpA within the scope of the 2009 ASAS (Assessment of Spondyloarthritis International Society) diagnostic criteria [15] were included in the study. Those with kidney disease, liver disease, and hematological disease were excluded. Age, gender, duration of illness, duration of treatment, serum CRP and ESR levels of last control visits, neutrophil, lymphocyte, and thrombocyte count, BASDAI scores (data on at least three months of biological therapy) were retrospectively recorded from the patients' electronic med- ical records. NLR and PLR values were calculated. Recorded laboratory results and clinical evaluations belonged to the same day. BASDAI assesses the patient's neck-back-waist-hip pain, pain and swelling in peripheral joints, and sensitivity levels with palpation at enthesis points. It is an index that evaluates the duration and level of morning stiffness with seven questions. The result is obtained by adding the mean value of the last two questions to the first five questions' total value. The score ranges from 0 to 10 . Its validity and reliability in Turkish have been demonstrated [16].

This study was approved by Haydarpaşa Numune Research and Training Hospital Ethics Committee (approval code: HNHAH-KAEK 2021/26).

\section{Statistical Analysis}

Data were analyzed with the IBM SPSS Statistics 22 (IBM SPSS, Turkey) program. Whether the data was normally distributed was evaluated using the Shapiro Wilk test. Descriptive statistics were presented as mean (standard deviation) and median (minmax) or percentage and frequency. Chi-square test, Fischer Exact Test were used for qualitative variables, and the Mann-Whitney U test was used for quantitative variables in comparison of data between groups. Spearman Correlation test was used to analyze whether there was a correlation between the data. Statistical significance was accepted as $p<0.05$.

\section{RESULTS}

The patients' mean age was 44 years (range: $23-67$ years), and the mean disease duration was 121.55 months (range: 7-408 months). Serum ESR levels were recorded as $15.2 \pm 13.6 \mathrm{~mm} / \mathrm{h}$, and CRP levels as $0.79 \pm 0.9 \mathrm{mg} / \mathrm{dl}$. Of the 33 patients included in the study, $42.4 \%(n=14)$ were on secukinumab therapy, while $57.6 \%(n=19)$ were on anti-TNF agents. There were no patients on synthetic disease-modifying drug therapy in both groups, but the patients temporarily took non-steroidal anti-inflammatory drugs during periods of activation. The male/female ratio was $6 / 8$ in the secukinumab group and $14 / 5$ in the anti-TNF group. There was no statistically significant difference between the two groups in terms of age, gender, or disease duration. $31.6 \%$ of the patients in the anti-TNF 
group had used another anti-TNF drug before. The duration of treatment was $27 \pm 27.6$ months (range: $3-72$ months) in the anti-TNF group. $71.4 \%(\mathrm{n}=10)$ of the patients receiving secukinumab had used at least one anti-TNF drug $(n=8)$ before, usually more than one. The duration of treatment was $8 \pm 5.1$ months (range: 3-19 months) in the secukinumab group. The duration of treatment in the secukinumab group was significantly shorter than in the anti-TNF group $(p=0.001)$. Only the NLR value was statistically significantly higher in the secukinumab group (Table 1). There was no correlation between NLR or PLR with CRP, ESR, or BASDAI values (Table 2).

\section{DISCUSSION}

In our study, NLR was higher in patients receiving secukinumab than those on anti-TNF therapy. In contrast, there was no significant difference between the two groups in ESR, CRP, BASDAI, and PLR.

ESR, CRP, and BASDAI parameters are widely used in follow-ups of patients with axial SpA for evaluating the response to treatment. In recent studies, it has been suggested that NLR and PLR can be used as easily accessible inflammation markers. These two values, which can be easily calculated as a result of hemogram studies, and are frequently applied in the routine, have been associated with systemic diseases

Table 1. Demographic data, clinical and laboratory findings of patients with axial SpA receiving anti-TNF or secukinumab treatment

\begin{tabular}{|c|c|c|c|}
\hline & Anti-TNF & Secukinumab & $p^{*}$ value \\
\hline & $\begin{array}{c}\text { mean } \pm \mathrm{SD} \\
\text { median (min-max) }\end{array}$ & $\begin{array}{c}\text { mean } \pm \text { SD } \\
\text { median }(\min -m a x)\end{array}$ & \\
\hline Age (years) & $\begin{array}{c}42.84 \pm 10.39 \\
42(23-65)\end{array}$ & $\begin{array}{c}45.57 \pm 11.76 \\
41(30-67)\end{array}$ & 0.733 \\
\hline Disease duration (months) & $\begin{array}{c}140.84 \pm 99.43 \\
132(8-312)\end{array}$ & $\begin{array}{c}65.36 \pm 102.42 \\
69(7-408)\end{array}$ & 0.152 \\
\hline $\begin{array}{l}\text { Treatment duration } \\
\text { (months) }\end{array}$ & $\begin{array}{l}27 \pm 27.6 \\
12(3-72)\end{array}$ & $\begin{array}{c}8 \pm 5.1 \\
7(3-19)\end{array}$ & 0.001 \\
\hline $\operatorname{ESR}(\mathrm{mm} / \mathrm{h})$ & $\begin{array}{c}12.42 \pm 11.98 \\
9(2-44)\end{array}$ & $\begin{array}{c}19.14 \pm 15.17 \\
9(2-57)\end{array}$ & 0.142 \\
\hline $\mathrm{CRP}(\mathrm{mg} / \mathrm{dl})$ & $\begin{array}{c}0.59 \pm 0.77 \\
0.2(0.2-3.1)\end{array}$ & $\begin{array}{c}1.08 \pm 1.15 \\
1.2(0.2-3.7)\end{array}$ & 0.186 \\
\hline $\begin{array}{l}\text { Neutophil count } \\
\left(10^{3} \times \text { cell } / \mathrm{mm}^{3}\right)\end{array}$ & $\begin{array}{l}4.56 \pm 1.62 \\
3.9(2.1-7.4)\end{array}$ & $\begin{array}{l}5.53 \pm 1.57 \\
2.9(3.6-8.6)\end{array}$ & 0.077 \\
\hline $\begin{array}{l}\text { Lymphocyte count } \\
\left(10^{3} \times \text { cell } / \mathrm{mm}^{3}\right)\end{array}$ & $\begin{array}{l}2.98 \pm 0.75 \\
2.8(1.8-4.3)\end{array}$ & $\begin{array}{l}2.62 \pm 0.84 \\
2.8(1.5-4.2)\end{array}$ & 0.174 \\
\hline $\begin{array}{l}\text { Platelet count } \\
\left(10^{3} \times \text { cell } / \mathrm{mm}^{3}\right)\end{array}$ & $\begin{array}{c}250.37 \pm 73.57 \\
240(104-450)\end{array}$ & $\begin{array}{c}269.43 \pm 55.83 \\
240(158-430)\end{array}$ & 0.174 \\
\hline NLR & $\begin{array}{c}1.56 \pm 0.46 \\
1.4(0.6-2.4)\end{array}$ & $\begin{array}{c}2.42 \pm 1.29 \\
1.4(0.8-5.12)\end{array}$ & 0.035 \\
\hline PLR & $\begin{array}{c}88.40 \pm 26.66 \\
(94.7)(24-125.4)\end{array}$ & $\begin{array}{c}111.52 \pm 36.07 \\
94.7(56.4-129.2)\end{array}$ & 0.142 \\
\hline BASDAI & $\begin{array}{c}2.68 . \pm .1 .87 \\
2.4(0-6.6)\end{array}$ & $\begin{array}{c}3.20 \pm 1.90 \\
3.50(0.2-6.4)\end{array}$ & 0.353 \\
\hline
\end{tabular}

$\mathrm{NLR}=$ neutrophil to lymphocyte ratio, $\mathrm{PLR}=$ platelet to lymphocyte ratio, $\mathrm{ESR}=$ erythrocyte sedimentation rate, $\mathrm{CRP}=\mathrm{C}-$ reactive protein, BASDAI $=$ Bath Ankylosing Spondylitis Disease Activity Index, $\mathrm{SD}=$ standart deviation, $p<0.05$ statistically significant. 
Table 2. Correlation results of NLR and PLR with ESR, CRP, and BASDAI

\begin{tabular}{lcc}
\hline Parameters & $\mathbf{r}$ & $\boldsymbol{p}$ value \\
\hline NLR-ESR & 0.272 & 0.126 \\
NLR-CRP & 0.317 & 0.073 \\
NLR-BASDAI & -0.248 & 0.195 \\
PLR-ESR & 0.130 & 0.471 \\
PLR-CRP & 0.234 & 0.190 \\
PLR-BASDAI & -0.249 & 0.192 \\
\hline
\end{tabular}

$\mathrm{NLR}=$ neutrophil to lymphocyte ratio, PLR: platelet to lymphocyte ratio, ESR = erythrocyte sedimentation rate, CRP $=\mathrm{C}$ reactive protein, BASDAI $=$ Bath Ankylosing Spondylitis Disease Activity Index, $p<0.05$ statistically significant.

such as malignancies, diabetes mellitus, and coronary artery disease [17-19]. In a study related to rheumatological conditions, NLR was significantly increased in polymyalgia rheumatica, polymyositis/dermatomyositis, systemic lupus erythematosus, rheumatoid arthritis, mixed connective tissue disease, primary sjögren's syndrome, osteoarthritis, and systemic sclerosis compared to the healthy population. It has been emphasized that PLR is higher in systemic lupus erythematosus and rheumatoid arthritis than in healthy individuals $[3,4]$. NLR and PLR are generally higher in patients with AS. [5, 6, 8-13]. There are much fewer studies on axial SpA in this area [1,7]. One showed that both NLR and PLR increased in patients with axial SpA than healthy controls [1]. On the other, only patients with axial SpA were evaluated, and there was no relationship between disease activity and NLR or PLR [7]. Since there was no healthy control group in our study and the patients were not grouped according to their disease activity levels, no conclusion could be reached on this issue.

The correlation analysis results in the studies mentioned above are also highly controversial. Correlation between NLR and PLR with laboratory parameters (ESR and CRP) was shown in most studies $[1,8,9$, $11,12]$. But the relationship with the clinical evaluation results (BASDAI, hand finger-to-ground distance, occiput-wall distance, modified Schober test) was not so common $[1,7,11,13]$. In our study, there was no correlation between NLR or PLR with clinical or laboratory evaluations. We think that this result is related to the small number of patients included in the study and the fact that most of the patients included in the study were in remission.
Few studies investigate the relationship between NLR and treatment in AS in the literature. But there was no research on PLR. A survey carried out in 35 patients with AS evaluated the anti-TNF therapy effectiveness with BASDAI, ESR, CRP, and NLR on 3rd months; there was an improvement in all parameters with treatment [12]. In another study, BASDAI, ESR, CRP, NLR values were found to be higher in patients with AS receiving only non-steroidal anti-inflammatory drugs $(n=72)$ compared to the group receiving anti-TNF treatment $(n=24)$ [13]. In our study, among the parameters evaluated in patients with axial SpA, only the NLR was significantly higher in the secukinumab group. BASDAI, CRP, and PLR values were also higher in the secukinumab group, but the difference was not statistically significant. The probable reason for the difference between the two groups is that the secukinumab group consisted of relatively active patients who could not achieve remission even though they used at least one, and usually more anti-TNF drugs. The anti-TNF group consisted of patients whose medical treatment and clinical status have been stable for a long time. However, considering that the only difference between the two groups is related to NLR, these results can be interpreted as NLR may be a useful and sensitive parameter for disease activity monitoring. We think that further data on much more cases are needed to speculate about the relationship of NLR with the pathway affected by the treatment.

\section{Limitations}

Our study's limitations are the small sample size, the absence of a control group, or the fact that the pa- 
tients were not grouped according to the disease activation criteria.

\section{CONCLUSION}

NLR may be a candidate parameter to be used for disease activity monitoring. In order to understand its effectiveness in evaluating the response to treatment, there is a need for studies in which comparisons are made in homogenized groups with larger numbers of patients, including the control group. Prospective studies would make valuable contributions in this area.

\section{Authors' Contribution}

Study Conception: EY, DGK; Study Design: EY, DGK; Supervision: EY, DGK; Funding: ŞEÖ, ŞE; Materials: EY, DGK; Data Collection and/or Processing: EY, DGK; Statistical Analysis and/or Data Interpretation: EY, DGK; Literature Review: EY, DGK; Manuscript Preparation: EY, DGK and Critical Review: EY, DGK.

\section{Conflict of interest}

The authors disclosed no conflict of interest during the preparation or publication of this manuscript.

\section{Financing}

The authors disclosed that they did not receive any grant during conduction or writing of this study.

\section{REFERENCES}

1. Huang Y, Deng W, Zheng S, Feng F, Huang Z, Huang Q, et al. Relationship between monocytes to lymphocytes ratio and axial spondyloarthritis. Int Immunopharmacol 2018;57:43-6.

2. Reveille JD. Biomarkers for diagnosis, monitoring of progression, and treatment responses in ankylosing spondylitis and axial spondyloarthritis. Clin Rheumatol 2015;34:1009-18.

3. Yang Z, Zhang Z, Lin F, Ren Y, Liu D, Zhong R, et al. Comparisons of neutrophil-, monocyte-, eosinophil-, and basophillymphocyte ratios among various systemic autoimmune rheumatic diseases. APMIS 2017;125:863-71.

4. Gasparyan AY, Ayvazyan L, Mukanova U, Yessirkepov M, Kitas GD. The platelet-to-lymphocyte ratio as an inflammatory marker in rheumatic diseases. Ann Lab Med 2019;39:345-57.

5. Zeb A, Khurshid S, Bano S, Rasheed U, Zammurrad S, Khan $\mathrm{MS}$, et al. The role of the neutrophil-to-lymphocyte ratio and platelet-to-lymphocyte ratio as markers of disease activity in ankylosing spondylitis. Cureus 2019;11:e6025.

6. Al-Osami MH, Awadh NI, Khalid KB, Awadh AI. Neutrophil/lymphocyte and platelet/lymphocyte ratios as potential markers of disease activity in patients with ankylosing spondylitis: a case-control study. Adv Rheumatol 2020;60:13.

7. Seng JJB, Kwan YH, Low LL, Thumboo J, Fong WSW. Role of neutrophil to lymphocyte ratio (NLR), platelet to lymphocyte ratio (PLR) and mean platelet volume (MPV) in assessing disease control in Asian patients with axial spondyloarthritis. Biomarkers 2018;23:335-8.

8. Bozan N, Alpaycı M, Aslan M, Cankaya H, Kıroğlu AF, Turan $\mathrm{M}$, et al. Mean platelet volume, red cell distribution width, platelet-to-lymphocyte and neutrophil-to-lymphocyte ratios in patients with ankylosing spondylitis and their relationships with high-frequency hearing thresholds. Eur Arch Otorhinolaryngol 2016;273:3663-72.

9. Kucuk A, Uslu AU, Ugan Y, Bagcaci S, Karahan AY, Akarmut A, et al. Neutrophil-to-lymphocyte ratio is involved in the severity of ankylosing spondylitis. Bratisl Lek Listy 2015;116:722-5. 10. Boyraz I, Koç B, Boyacı A, Tutoğlu A, Sarman H, Ozkan H. Ratio of neutrophil/lymphocyte and platelet/lymphocyte in patient with ankylosing spondylitis that are treating with anti-TNF. Int J Clin Exp Med 2014;7:2912-5.

11. Mercan R, Bitik B, Tufan A, Bozbulut UB, Atas N, Ozturk $\mathrm{MA}$, et al. The association between neutrophil/lymphocyte ratio and disease activity in rheumatoid arthritis and ankylosing spondylitis. J Clin Lab Anal 2016;30:597-601.

12. Coşkun BN, Öksüz MF, Ermurat S, Tufan AN, Oruçoğlu N, Doğan A, et al. Neutrophil lymphocyte ratio can be a valuable marker in defining disease activity in patients who have started anti-tumor necrosis factor (TNF) drugs for ankylosing spondylitis. Eur J Rheumatol 2014;1:101-5.

13. Gökmen F, Akbal A, Reşorlu H, Gökmen E, Güven M, Aras $\mathrm{AB}$, et al. Neutrophil-lymphocyte ratio connected to treatment options and inflammation markers of ankylosing spondylitis. J Clin Lab Anal 2015;29:294-8.

14. Koenders MI, Lubberts E, van de Loo FA, Oppers-Walgreen B, van den Bersselaar L, Helsen MM, et al. Interleukin-17 acts independently of TNF-alpha under arthritic conditions. J Immunol 2006;176:6262-9.

15. Rudwaleit M, van der Heijde D, Landewé R, Listing J, Akkoc $\mathrm{N}$, Brandt J, et al. The development of Assessment of SpondyloArthritis international Society classification criteria for axial spondyloarthritis (part II): validation and final selection. Ann Rheum Dis 2009;68:777-83.

16. Ay S, Kutlay Ş, Kurtaiş Y, Yanık B. Adaptation and validation of the Turkish version of the bath ankylosing spondylitis disease activity index (BASDAI). Arch Rheumatol 2004;19:139-46.

17. Sari I, Sunbul M, Mammadov C, Durmuş E, Bozbay M, Kivrak $\mathrm{T}$, et al. Relation of neutrophil-to-lymphocyte and platelet-to-lymphocyte ratio with coronary artery disease severity in patients undergoing coronary angiography. Kardiol Pol 2015;73:1310-6.

18. Demirdal T, Sen P. The significance of neutrophil-lymphocyte ratio, platelet-lymphocyte ratio and lymphocyte-monocyte ratio 
in predicting peripheral arterial disease, peripheral neuropathy, osteomyelitis and amputation in diabetic foot infection. Diabetes Res Clin Pract 2018;144:118-25.

19. Guo W, Lu X, Liu Q, Zhang T, Li P, Qiao W, et al. Prognostic value of neutrophil-to-lymphocyte ratio and platelet-to-lymphocyte ratio for breast cancer patients: an updated meta-analysis of 17079 individuals. Cancer Med 2019;8:4135-48. 